(RESEARCH ARTICLE)

\title{
Indications and findings in patients referred for endoscopy in a private health centre in Sokoto, Northwestern Nigeria
}

\author{
Maiyaki Abubakar Sadiq ${ }^{1, *}$ and Bamaiyi Adamu Jibril 2 \\ ${ }^{1}$ Department of Internal Medicine, Usmanu Danfodiyo University Teaching Hospital, Sokoto, Nigeria. \\ 2 Department of Physiology, Usmanu Danfodiyo University, Sokoto, Nigeria.
}

Publication history: Received on 15 June 2020; revised on 21 June 2020; accepted on 23 June 2020

Article DOI: https://doi.org/10.30574/wjarr.2020.6.3.0204

\begin{abstract}
Upper gastrointestinal tract symptoms are associated with a major morbidity and mortality globally. Endoscopy offers direct visualization of the pathology and enables both diagnostic and therapeutic interventions. Request for the procedure is on the increase probably due to exposure to more risk factors or because of increased awareness about the disease. We aimed to study the indications and findings in patients referred for endoscopy. We enrolled a total of 1747 patients between January 2013-December 2019.Their demographic characteristics and findings on endoscopy were extracted from the endoscopy register. Males constituted 937 (53.7\%), with a mean age of $42.50 \pm 14.13$ and females $41.38 \pm 16.73$. The age range of patients was $15-87$ years. The commonest indication was dyspepsia $1122(64.2 \%)$.There was no significant statistical difference between gender with respect to dyspepsia $(\chi 2=0.8511 \mathrm{p}-$ value $=0.3563$. Upper gastro-intestinal bleeding (UGIB) was the second most common 10.3\%, Gastroesophageal reflux disease (GERD) 9.9\%, and chronic liver disease (CLD) 8.0\%.There was significant statistical difference in gender presentation of UGIB ( $\chi 2=6.49 \mathrm{p}$-value $=0.0109$ and CLD $\chi 2=21.109 \mathrm{p}$-value $=0.00001)$.Gastritis was the predominant endoscopic finding, 628(35.9\%). Esophageal varices were the c ommonest etiologic finding for UGIB (51.6\%) and commoner in males $(\chi 2=11.083$ p-value $=0.0009)$, then gastric and duodenal ulcers, $11.4 \%$ and $2.7 \%$ respectively. Hiatus hernia was 157(9.0\%) Upper gastrointestinal malignancies were 2.4\%. In conclusion, dyspepsia is a common clinical presentation in patients with GIT symptoms. Variceal bleeding is a significant cause of UGIB, therefore early endoscopic CLD screening will help reduce morbidity and mortality in Nigeria.
\end{abstract}

Keywords: Indications; Findings; Endoscopy; Health-centre; Northwestern; Nigeria

\section{Introduction}

Symptoms referred to the upper gastrointestinal tract are a very common complaints among patients in both general and in gastroenterology practice in sub-Saharan Africa and world-wide. [1]. The risk factors for the syndrome includes Helicobacter pylori infection, indiscriminate use of non-steroidal anti-inflammatory drugs (NSAIDs), CLD, alcoholism, Zollinger-Ellison syndrome as well as genetic predisposition among others [2,3]. It is associated with a major morbidity and mortality ranging from $2 \%$ to $33 \%$ [4,5]. Upper gastrointestinal (UGI) symptoms are also associated with a major daily manpower loss, a significant health care cost to the patients, especially that most patients pay-out-of-pocket to access medical care in Nigeria [6]. Studies in Ghana showed dyspepsia to be the commonest indications for upper gastrointestinal endoscopy (UGIE) [1,7]. Similarly several studies in Nigeria have showed dyspepsia to be the commonest indication for UGIE [8,11]. UGIE is a procedure of choice in the management of UGI symptoms [11, 12]. Symptoms as related to structural lesions may occur at the level of esophagus, stomach or duodenum [3]. Oluwagbenga and colleagues in Ado-Ekiti [13] reported gastritis to be the commonest endoscopic findings in patients referred for UGIE (28.2\%) while Onyekwere [9] in Lagos South-western Nigeria reported GERD as the commonest endoscopic findings [10]. Picardo et al in South-eastern a Nigeria reported gastritis (76.3\%) and peptic ulcer disease (PUD) (18.5\%)

\footnotetext{
* Corresponding author: Maiyaki Abubakar Sadiq
} 
as the commonest structural lesions on endoscopy. The surge in UGI problems may due to; increased awareness and availability of facilities, and increased expertise to run the procedures.

Endoscopy is now becoming readily available in many public and private hospitals in Nigeria. Clinical evaluation alongside diagnostic and therapeutic endoscopy will lead to more efficient treatment and consequently reduced morbidity and mortality. The increasing number of expertise in handling this procedure is encouraging [12]. However, this may not be the case in Sokoto, Northwest Nigeria where endoscopic facilities for both diagnostic and therapeutic management became readily available only about a decade ago. Presently, only three health facilities provide endoscopic services to Sokoto, Zamfara, Kebbi and Niger States which has a population of over ten million [14]. Thus, the aim of this study was to look at the indications and findings in patients referred for endoscopy in a health center during a seven year period.

\section{Methodology}

This is a cross-sectional descriptive study that report the indications and findings of endoscopy among 1,747 patients seen at Medistop Clinical Diagnostic Centre, Sokoto, Northwest Nigeria, between January, 2013 and December, 2019. The ethical approval to undertake the research was obtained from the management of the hospital and its referenced MCD/ECR/2012/ Vol.1/17.

All the patients were administered a questionnaire to evaluate for symptoms of GERD. Each consenting patient was requested to observe overnight fast, for at least 8 hours. At endoscopy, the pharynx was anaesthetized with $10 \%$ of xylocaine spray. Then, the shaft of the endoscope was lubricated with K-Y gel and endoscopy was performed on each patient using a forward viewing fibre-optic Olympus GIFQ-140 series video gastroscope. Conscious sedation was not done routinely pre-procedure, except in some restive patients where intravenous midazolam was administered accordingly.

All the endoscopies were carried by an experienced gastroenterologist and findings were recorded.

\subsection{Statistical analysis}

Data storage and analysis was done with IBM SPSS software (version 22 for windows Inc., Chicago, IL, USA). Mean and standard deviations was computed for quantitative variables and non-parametric equivalents was used for qualitative variables. Chi-square goodness of fit analysis was used to ascertain that the provisional diagnosis and endoscopic findings are not incidental occurrences. A two-sided P-value of $<0.05$ was considered as minimum level statistical significance.

\section{Results}

The present study analyzed the endoscopic reports of 1,747 consecutive consenting patients referred for UGIE. The mean age of the patients was $41.98 \pm 15.40$ year with age range of $15-87$ years. The male patients constituted $53.7 \%$ $(937 / 1747)$. The mean age of the male patients was $42.50 \pm 14.13$ years, which was not statistically significant from the mean for the female patients, $41.38 \pm 16.73$ years ( $p$-value $=0.1462$ ).

Table 1 Frequencies of various indications for endoscopy

\begin{tabular}{llll}
\hline Indications & Frequency (\%) & & \\
\hline & TOTAL & MALES & FEMALES \\
Dyspepsia & $1122(64.2)$ & $549(58.6)$ & $573(70.8)$ \\
UGIB & $182(10.3)$ & $107(11.3)$ & $75(9.2)$ \\
GERD & $173(9.9)$ & $94(10.0)$ & $79(9.8)$ \\
CLD & $140(8.0)$ & $107(11.4)$ & $33(4.1)$ \\
Abdominal pain & $20(1.1)$ & $12(1.3)$ & $8(1.0)$ \\
Gastric Ca & $20(1.1)$ & $13(1.4)$ & $7(0.8)$ \\
Dysphagia & $12(0.8)$ & $8(0.9)$ & $4(0.5)$ \\
Oesophageal Ca & $12(0.7)$ & $10(1.1)$ & $2(0.3)$ \\
Others & $66(4.0)$ & $37(4.0)$ & $29(3.5)$ \\
\hline
\end{tabular}


Dyspepsia was the commonest indication for endoscopy alongside UGIB. Other reasons for the referral which included recurrent vomiting, abdominal pains, anemia of unknown cause, weight loss, and chronic diarrhea among others were rare, in the present group of patients.

More male patients presented with provisional diagnosis of CLD and UGIB than the proportions seen among the female patients (11.4\% Vs 4.1\% and $11.5 \%$ Vs 6.8\%, respectively, $\mathrm{P}<0.05)$ (see table 1 ).

Table 2 Chi-square goodness of fit statistics for the four most frequent referrals for endoscopy

\begin{tabular}{llllll}
\hline Indication & Sex & \% & $\chi^{\mathbf{2}}$ & Df & P-Value \\
\hline Dyspepsia & M & 49.1 & 0.8511 & 1 & 0.3563 \\
& F & 50.9 & & & \\
GERD & M & 54.4 & 0.0197 & 1 & 0.8884 \\
& F & 45.6 & & & \\
CLD & M & 76.6 & 21.0919 & 1 & $<0.0001$ \\
& F & 23.4 & & & \\
UGIB & M & 66.4 & 6.49 & 1 & 0.0109 \\
& F & 33.6 & & & \\
\hline
\end{tabular}

There was no statistical difference between genders in terms of the clinical presentation of dyspepsia. $(\mathrm{P}$-value $=$ 0.3563), however there was significant statistical difference in gender presentation of CLD and UGIB.

Table 3 Frequencies of various endoscopic findings in our centre

\begin{tabular}{llll}
\hline Findings & Frequency (\%) & & \\
\hline & TOTAL & MALES & FEMALES \\
Gastritis & $628(35.9)$ & $311(33.2)$ & $317(39.1)$ \\
Gastric ulcer & $200(11.4)$ & $110(11.7)$ & $90(11.1)$ \\
Erosive esophagitis & $191(10.9)$ & $93(9.9)$ & $98(12.1)$ \\
Esophageal varices & $159(9.1)$ & $117(12.5)$ & $42(5.2)$ \\
Hiatus hernia & $157(9.0)$ & $79(8.4)$ & $78(9.6)$ \\
Normal upper GI & $150(8.6)$ & $70(7.5)$ & $80(9.9)$ \\
Duodenitis & $91(5.2)$ & $52(5.5)$ & $39(4.8)$ \\
Duodenal ulcer & $47(2.7)$ & $28(3.0)$ & $19(2.3)$ \\
Gastric Ca & $37(2.1)$ & $26(2.8)$ & $11(1.4)$ \\
Candida esophagitis & $28(1.6)$ & $18(1.9)$ & $10(1.2)$ \\
Esophageal Ca & $14(0.8)$ & $10(1.1)$ & $4(0.5)$ \\
Others & $45(2.6)$ & $23(2.5)$ & $22(2.7)$ \\
\hline
\end{tabular}

Gastritis and Gastric ulcer were the commonest findings among patients referred for endoscopy in our centre (35.9\% and $11.4 \%$, respectively). UGI malignancies were rare. 
Table 4 Chi-square goodness of fit statistics for the ten most frequents findings on endoscopic among the patients

\begin{tabular}{|c|c|c|c|c|c|}
\hline Findings & Sex & $\%$ & $\chi^{2}$ & Df & P-Value \\
\hline \multirow[t]{2}{*}{ Gastritis } & $\mathrm{M}$ & 49.7 & 0.64 .35 & 1 & 0.4224 \\
\hline & $\mathrm{F}$ & 50.3 & & & \\
\hline \multirow[t]{2}{*}{ Gastric ulcer } & $\mathrm{M}$ & 54.9 & 0.0579 & 1 & 0.8098 \\
\hline & $\mathrm{F}$ & 45.1 & & & \\
\hline \multirow[t]{2}{*}{ Esophageal varices } & $\mathrm{M}$ & 73.8 & 16.2494 & 1 & $<0.0001$ \\
\hline & $\mathrm{F}$ & 26.2 & & & \\
\hline \multirow[t]{2}{*}{ Hiatus hernia } & $\mathrm{M}$ & 50.3 & 0.4649 & 1 & 0.4953 \\
\hline & $\mathrm{F}$ & 49.7 & & & \\
\hline \multirow[t]{2}{*}{ Erosive esophagitis } & $\mathrm{M}$ & 47.1 & 1.75 & 1 & 0.1856 \\
\hline & $\mathrm{F}$ & 52.9 & & & \\
\hline \multirow[t]{2}{*}{ Normal upper GI } & $\mathrm{M}$ & 52.3 & 0.0788 & 1 & 0.7789 \\
\hline & $\mathrm{F}$ & 47.7 & & & \\
\hline \multirow[t]{2}{*}{ Duodenitis } & $\mathrm{M}$ & 57.3 & 0.5212 & 1 & 0.4703 \\
\hline & $\mathrm{F}$ & 42.7 & & & \\
\hline \multirow[t]{2}{*}{ Duodenal ulcer } & $\mathrm{M}$ & 59.1 & 1.1728 & 1 & 0.2788 \\
\hline & $\mathrm{F}$ & 40.9 & & & \\
\hline \multirow[t]{2}{*}{ Gastric Ca } & $\mathrm{M}$ & 70.3 & 11.083 & 1 & 0.0009 \\
\hline & $\mathrm{F}$ & 29.7 & & & \\
\hline
\end{tabular}

Esophageal varices represented a significant finding among the male patients compared to the females (73.8\% Vs $\left.26.2 \%, \chi^{2}=16.2494, \mathrm{df}=1, \mathrm{p}<0.0001\right)$.

\section{Discussion}

Availability of endoscopic facilities have undoubtedly significantly revolutionized the diagnosis and therapeutic management of most gastrointestinal diseases worldwide. Chronic gastrointestinal illnesses, such as non-infectious gastric ulcer disease, cancer, dyspepsia and CLD are on the rise and have created an increased demand for endoscopic services [15]. UGIE became available about a decade ago in our study area. The present study analyzed the endoscopic reports of 1,747 consecutive consenting patients referred for UGIE. The mean age of the patients was $41.98 \pm 15.40$ year with age range of 15 - 87 years. The male patients constituted 53.7\% (937/1747). The mean age of the male patients was $42.50 \pm 14.13$ years, which was not statistically different from the mean for the female patients, $41.38 \pm 16.73$ years (p-value $=0.1462$ ). The study showed a male preponderance which is similar to several studies in Nigeria $[10,13,16$, $17,18]$, however other studies quoted a female preponderance. [5, 7, 19 20].The findings in the present study showed that our patients were younger compared to other studies elsewhere including some parts of Nigeria [1, 12, 21]. Indeed, male populations with UGI symptoms tend to present at a younger age than their female counterparts as shown in the present study and it corroborated with the study reported in Tripoli, Libya [21]. This phenomenon may not be unconnected to the increase tendencies in young male individuals to the risk of upper UGI problems such as indiscriminate ingestion of NSAIDs and cigarette smoking [5, 21].

Endoscopy is yet to be classified amongst the least of investigations under the National Health Insurance Scheme in Nigeria and thus most patient pay-out-of-pocket to access endoscopic evaluations. It is a known fact that males are economically more viable and have a higher purchasing power as compared to females in a typical African and resource poor setting. This may explain the male preponderance as was seen in this and other studies. 
The commonest indication for UGIE amongst our patient population was dyspepsia (64.2\%) There was no significant statistical difference between gender presentation of dyspepsia $(\chi 2=0.8511 p$-value 0.3563$)$. Several studies in Nigeria [10, 13 16] in Egypt, [22] and in Kenya[23] found dyspepsia to be the leading cause of referral for UGIE. Approximately $40 \%$ of dyspeptic patients have an organic cause and only $20 \%$ of patients have a significant gastroduodenal lesion as peptic ulcer disease [22]. UGIB was the second most common indication for referral (10.3\%), then GERD (9.9\%) and CLD (8.0\%). Interestingly, there was significant statistical difference in gender presentation of UGIB $(\chi 2=6.49 \mathrm{p}$-value $0.0109)$ and CLD $(\chi 2=21.109 \mathrm{p}$-value $<0.0001)$ in males as compared to females. Onyekwere in Lagos [9] South-western Nigeria also found UGIB to be the second leading request for endoscopy.

Gastritis was the most frequent endoscopic finding in our patient population 628 (35.9\%) followed by gastric ulcer 200 (11.4\%) and erosive oesophagitis 191 (10.9\%) which is similar to findings by Gyedu et al [7] in Kumasi, Ghana. However Ismaila et al in Jos Plateau [24] and Picardo [10] in Enugu found gastritis and duodenitis as their most frequent endoscopic findings. Onyekwere [9] in Lagos found erosive esophagitis as the third leading endoscopic finding as was seen in this study. It is now a known fact that GERD may not be rare as was previously thought in Nigeria and individuals of African descent [25]. We reported gastric ulcers to be the second most predominant endoscopic finding 200 (11.4\%) compared to duodenal ulcer which was 47 (2.7\%). This was similar to findings in Enugu, South-eastern Nigeria [10] and in Ghana $[1,7]$ but contrary to other studies which showed duodenal ulcers to be commoner in several other studies $[13,17,19,26]$. This may not be unconnected with the fact that NSAIDS are over the counter medications in Nigeria and easily accessible for pain management generally. Although NSAIDS can cause lesions in both parts of the gastrointestinal tracts, gastric lesions are commoner. Another major factor may 0be the high prevalence rate of $\mathrm{H}$ pylori in Nigeria in several reports $[27,28,29,30]$.The indication for UGIB (hematemesis, malena, Hematochezia) was seen in $10.3 \%$ with males predominating $((\chi 2=16.2494 \mathrm{p}$-value 0.0001). Esophageal varices commonly develop as a result of hemodynamic abnormality that causes portal hypertension. Oesophageal varices were the commonest etiologic finding for UGIB accounting for $51.6 \%$ and commoner in males $(\chi 2=11.083 \mathrm{p}$-value 0.0009$)$ followed by gastric ulcer, duodenal ulcer, gastric cancer and severe gastritis at $23.1 \%, 7.7 \%, 4.4 \%$ and $2.7 \%$ respectively. Bleeding was obscured in $19 \%$ of patients with UGIB. This figure was much higher compared to other studies [22, 31,32].The reasons for this may include late presentation to seek healthcare especially in a low income poor resource settings after onset of symptoms, poor accessibility to endoscopic facilities and personnel, and most patients pay-out-of-pocket to access medical care in Nigeria. It is also a known fact that mucosal lesions heal quickly and generally the time interval between the bleeding episode and endoscopy can influence the endoscopic diagnosis. The male preponderance in patients that presented with UGIB that was observed in this study was similar to studies by Olokoba et al in Ilorin [12] and Ajayi et al in Ekiti [31]. The finding of esophageal varices being the commonest cause of UGIB is similar to findings [11] in Maiduguri in Northern Nigeria [32], Egypt [33] and in Qatar [34]. However, this is in contrast with other studies in the Southern parts of Nigeria where peptic ulcer disease and gastric erosions were the commonest etiologic agents for UGIB, [7, 35]. Esophageal varices develops as a complication of CLD which eventually can lead to UGIB.CLD was seen in 8\% of the studied patients. It can result as a chronic sequelae of Hepatitis B and C infections which has a high prevalence in this region.

Hiatus hernia presents with UGI symptoms but majority may be asymptomatic especially when anatomically small. Studies in Nigeria report a prevalence range of between 3.3-28\%- [31, 36] in Nigerians. A recent study in the NigerDelta region of Nigeria showed a prevalence rate of $20.1 \%$ [37], while another European study quoted 21.2\%) [38]. In this study, the prevalence of hiatus hernia was $9.0 \%$ with no significant statistical difference in gender $((\chi 2=0.4649 \mathrm{p}$ value 0.4953 ) which is in concordance with an earlier study [39] in North-western Nigeria.

Upper gastrointestinal malignancies are not uncommon in Nigeria. In this study, suspected UGI malignancies constituted $2.9 \%$ of the total number of patients studied with gastric accounting for $37(2.1 \%)$ and esophageal $14(0.8 \%)$. This is similar to findings by [40] in Northern-western Nigeria in which UGI prevalence was found to be $2.4 \%$ (gastric $1.4 \%$ and esophageal $1.0 \%$ ) amongst patients who underwent UGIE. Normal endoscopy was seen in (8.6\%) with an overall diagnostic yield of $91.4 \%$ which is similar to findings by Ray-Offor [18] who reported a yield of $90 \%$. Picardo and Ajayi [10] reported a diagnostic yield of $87.2 \%$ in Enugu. These variation may be due to varying indications, improved and better understanding and differentiation of Functional from dyspepsia of organic causes and time duration between onset of gastrointestinal symptoms and the endoscopic procedure.

\section{Conclusion}

The present study indicates that dyspepsia and upper gastrointestinal bleeding were the commonest indications for referral for upper gastrointestinal endoscopy. Interestingly, gastritis and gastric ulcers were the most predominant endoscopic findings. Helicobacter pylori infection is a known etiologic agent for diseases thus the "test and treat" approach by attending physicians. This is important for policy makers and administrators as facility for $\mathrm{H}$. pylori testing 
are not readily available in most of our hospitals. Esophageal varices were commoner than gastric/duodenal ulcers in causing upper gastrointestinal bleeding in our study area which is contrary to findings in the Southern parts of the country. Endoscopy should be made mandatory as a screening tool in Chronic liver diseases to aid early detection of varices thus reducing morbidity and mortality associated with upper gastrointestinal bleeding.

\section{Compliance with ethical standards}

\section{Acknowledgments}

We are grateful to our patients for consenting to participate in the study, and we sincerely thank the management of the Medistop Clinical Diagnostic Centre for providing the facilities during the seven years research period. We also appreciate their ethical committee, for approving our ethical application.

\section{Disclosure of conflict of interest}

All authors declare no conflict of interest.

\section{Statement of ethical approval}

The present research was approved by the ethical committee of Medistop Clinical Diagnostic Centre Sokoto with reference number MCD/ECR/2012/ Vol.1/17.

\section{Statement of informed consent}

Informed consent was obtained from all individuals who voluntarily participated in the study.

\section{References}

[1] Agyei-Nkansah A, Duah A and Alfonso M. (2019). Indications and findings of upper gastrointestinal endoscopy in patients presenting to a District Hospital, Ghana. The Pan Afr Med J, 34, 82, 18002.

[2] Sverdén E, Agréus L, Dunn JM and Lagergren J. (2019). Peptic ulcer disease. BMJ, 367, 15495.

[3] Malik TF and Gnanapandithan KS. (2020). Peptic Ulcer Disease. [Updated 2020 Feb 15]. ed. Treasure Island (FL):: In: StatPearls [Internet].

[4] Stanley AJ and Laine L. (2019). Management of acute upper gastrointestinal bleeding. BMJ, 364, 1536.

[5] Moledina SM and Komba E. (2017). Risk factors for mortality among patients admitted with upper gastrointestinal bleeding at a tertiary hospital: a prospective cohort study. BMC Gastroenterol, 17(1), 165.

[6] Ogah OS, Stewart S, Onwujekwe OE, Falase AO, Adebayo SO, Olunuga T and Sliwa K. (2014). Economic burden of heart failure: investigating outpatient and inpatient costs in Abeokuta, Southwest Nigeria. PloS one, 9(11), e113032-e.

[7] Gyedu A and Yorke J. (2014). Upper gastrointestinal endoscopy in the patient population of Kumasi, Ghana: Indications and findings. Pan Afr Med J, 18, 327.

[8] Agbakwuru EA, Fatusi AO, Ndububa DA, Alatise OI, Arigbabu OA and Akinola DO. (2006). Pattern and validity of clinical diagnosis of upper gastrointestinal diseases in South-West Nigeria. Afr Health Sci, 6(2), 98-103.

[9] Onyekwere CA, Hameed H, Anomneze EE and Chibututu C. (2008). Upper gastrointestinal endoscopy findings in Nigerians: a review of 170 cases in Lagos. Nig Postg Med J, 15(2), 126-9.

[10] Picardo N and Ajayi N. (2015). Indications for an endoscopic findings in patients with symptoms of upper gastrointestinal disease in a Tertiary Hospital in South-Eastern Nigeria. Afr J Med Health Sci, 14(2), 96-100.

[11] Mustapha S, Ajayi N, Jibrin Y and Shehu A. (2009). Aetiology of Upper Gastrointestinal Bleeding in North-Eastern Nigeria: A Retrospective Review of Endoscopic Findings. Nig J Gastroenterol Hepatol, 1(2).

[12] Olokoba AB, Olokoba L, Jimoh A, Salawu F, Danburam A and Ehalaiye B. (2009). Upper gastrointestinal tract endoscopy indications in Northern Nigeria. J College of Physc and Surg Pak, 19, 327-8. 
[13] Oluwagbenga 00, Musah Y, Paul O, Olagoke E, Oladipo 0, Osisiogu SM, Adenike 00, Banjo OH, Elijah AO and Alex AS. (2020). Upper Gastrointestinal Endoscopy In Ido-Ekiti, Nigeria: A Four-Year Review. Open J Gastroenterol and Hepatol, 3, 35.

[14] NPC N. (2007). Report of Nigeria's National Population Commission on the 2006 Census. Population and Development Review, 33(1), 206-10.

[15] Nwokediuko SC, Ijoma U, Obienu 0 and Picardo N. (2012). Time trends of upper gastrointestinal diseases in Nigeria. Ann Gastroenterol, 25(1), 52-6.

[16] Mustapha SK, Kida IM, Dayar A and Gundiri LB. (2010). Indications for Upper gastrointestinal Endoscopy in Maiduguri, North-Eastern Nigeria.Borno Medical Journal. Borno Med, 7, 16-8.

[17] Jeje E, Olajide T and Akande B. (2013). Upper gastrointestinal endoscopy - Our findings, our experience in Lagoon hospital, Lagos, Nigeria. Macedonian Journal of Medical Sciences, 6, 168-73.

[18] Ray-Offor E and Obiorah CC. (2014). Upper Gastro-Intestinal Endoscopy in Port Harcourt, Nigeria: An Audit. Nigerian Health Journal, 14(3), 134-139.

[19] Aduful H, Naaeder S, Darko R, Baako B, Clegg-Lamptey J, Nkrumah K, et al. (2007). Upper gastrointestinal endoscopy at the Korle Bu Teaching Hospital, Accra, Ghana. Ghana Med J, 41(1), $12-6$.

[20] Ismaila Khurram M, Khaar HT, Hasan Z, Umar M, Javed S, Asghar T, et al. (2003). A 12 years audit of upper gastrointestinal endoscopic procedures. J Coll Physc Surg Pak, 13(6), 321-4.

[21] Elghuel A. (2011). The characteristics of adults with upper gastrointestinal bleeding admitted to Tripoli Medical Center: A retrospective case-series analysis. Libyan J Med, 6, 10.3402.

[22] Gado A, Ebeid B, Abdelmohsen A and Axon A. (2015). Endoscopic evaluation of patients with dyspepsia in a secondary referral hospital in Egypt. Alexandria J Med, 51(3), 179-84.

[23] Ayuo PO, Some FF and Kiplagat J. (2014). Upper gastrointestinal endoscopy findings in patients referred with upper astrointestinal symptoms in Eldoret, Kenya: A retrospective review. East Afr Med J, 91(8), 267-73.

[24] Ismaila BO and Misauno MA. (2016). Gastrointestinal dyspepsia in a secondary referral hospital in Egypt. Alexandria J Med, 51(3), 179-84.

[25] Maiyaki AS, Yakubu A, Aminu MS, Umar H, Balarabe SA, Bamaiyi AJ, Abdullahi IA and Usman MZ. [2020]. Endoscopic correlation of clinical presentation of gastroesophageal reflux disease among pateinets referred for gastroscopy in a tertiary hospital. World Journal of Advanced Research and Reviews, 06(02), 37-43.

[26] Ndububa DA, Agbakwuru AE, Adebayo RA, Olasode BJ, Olaomi 00, Adeosun OA, et al. (2001). Upper gastrointestinal findings and incidence of Helicobacter pylori infection among Nigerian patients with dyspepsia. West Afri J of Med, 20(2), 140-5.

[27] Aboderin OA, Abdu AR, Odetoyin B, Okeke IN, Lawal OO and Ndububa DA. (2007). Antibiotic resistance of Helicobacter pylori from patients in Ile-Ife, South-west, Nigeria. Afri Health Sci, 7(3), 143-7.

[28] Jemilohun AC, Otegbayo JA, Ola SO, Oluwasola OA and Akere A. (2011). Prevalence of Helicobacter pylori among Nigerian patients with dyspepsia in Ibadan. The Pan Afr Med J, 6, 18-25.

[29] Ajayi A. (2015). Effectiveness of Triple Therapy Regimens in the Eradication of Helicobacter pylori in Patients with Uninvestigated Dyspepsia in Ekiti State, Nigeria. British Journal of Medicine \& Medical Research, 6, 278-85.

[30] Bello AK, Umar AB and Borodo MM. (2018). Prevalence and risk factors for helicobacter pylori infection in gastroduodenal diseases in Kano, Nigeria. Afr J Medical and Health Sci, 17, 41-46.

[31] Ajayi A. (2013). Aetiology and Management Outcome of Upper Gastrointestinal Bleeding in Adult Patients Presenting at Ekiti State University Teaching Hospital, Ado-Ekiti, Nig Greener J Medical Sci, 3, 093-7.

[32] Jaka H, Koy M, Liwa A, Kabangila R, Mirambo M, Scheppach W, et al. (2012). A fibreoptic endoscopic study of upper gastrointestinal bleeding at Bugando Medical Centre in Northwestern Tanzania: a retrospective review of 240 cases. BMC Res Notes, 5, 200.

[33] Gado A, Ebeid B, Abdelmohsen A and Axon A. (2012). Clinical outcome of acute upper gastrointestinal haemorrhage among patients admitted to a governmant hospital in Egypt. Saudi J Gastroenterol, 18(1), 34-39.

[34] Kanha A, Al Kaabi S and Sattar HA. (2003). Upper gastrointestinal bleeding in the Medical Intensive Care Unit Doha, Qatar: A one-year survey. Qatar Med J, 22-27. 
[35] Ugiagbe R and Omuemu C. (2016). Etiology of upper gastrointestinal bleeding in the University of Benin Teaching Hospital, South-Southern Nigeria. Nig J Surg Sci, 26, 29-32.

[36] Ismaila B, Ale A, Ojo E, Misauno M and Sule A. (2017). Hiatus Hernia in Nigerians - An Endoscopic Study. J Surg Transplant Sci, 5(1), 1048.

[37] Ray-Offor E and Falase B. (2020). Hiatus hernia and erosive oesophagitis at endoscopy in Nigerian patients. World Journal of Advanced Research and Reviews, 5(3), 163-9.

[38] Sgouros SN, Mpakos D, Rodias M, Vassiliades K, Karakoidas C, Andrikopoulos E, et al. (2007). Prevalence and axial length of hiatus hernia in patients, with nonerosive reflux disease: a prospective study. Journal of clinical gastroenterology, 41(9), 814-818.

[39] Maiyaki A, Yakubu A, Bashar B, Umar H, Aminu M, Balarabe S and Liman MH. (2020). Endoscopic profiling of patients with dyspepsia in North-western Nigeria. A four-year review International Journal of Biological \& Medical Research, 11(1), 6945-6949.

[40] Tijjani B, Borodo MM and Samaila AA. (2009). Upper Gastrointestinal cancers at endoscopy in Kano, NorthWestern Nigeria. Nig J Med Pract, 56(2), 1-2.

\section{How to cite this article}

Maiyaki AS and Bamaiyi AJ. (2020). Indications and findings in patients referred for endoscopy in a private health centre in Sokoto, Northwestern Nigeria. World Journal of Advanced Research and Reviews, 6(3), 289-296. 